\title{
Giant Verrucae Vulgaris: Provoked by Long Term Topical Glucocorticoids?
}

\author{
Yang Yang a, b, Hui-Jun Ma a, b, c, Rong Huª Lian-Jin Songa, \\ Ting-Hui Li ${ }^{a}$, Chi-Yu Jia ${ }^{a}$
}

\begin{abstract}
We report a 49-year-old man suffered from giant verrucae vulgaris over shin of his left leg. The lesion had arisen with some maculopapules and misdiagnosed as eczema 4 years previously. After 4 years continuous topical glucocorticoids treatment, the eruption had gradually progressed to a $5 \times 5 \mathrm{~cm}$ sized plaque covered with some nodules and crusts. Histopathologic examination confirmed the diagnosis of giant verrucae vulgaris. The discontinue therapy with glucocorticoids stopped the development of the lesion, which was totally healed by cryotherapy and topical imiquimod 6 months late. We suggest that topical glucocorticoids continuously for a long-term may contribute to the formation of giant verrucae vulgaris.
\end{abstract}

Keywords: Giant verrucae vulgaris; Topical glucocorticoids; $\mathrm{Hu}-$ man papilloma virus

\section{Introduction}

Verrucae vulgaris (VV), also known as common wart, are the one of proliferative virus dermatopathy infected and produced by human papilloma virus (HPV). It represents the most frequent clinical lesions as the hyperkeratotic papulonodules that can be seen anywhere on the glabrous skin [1]. However, there are few cases of giant verrucae vulgaris (GVV) reported in the published work and its pathogenesis is largely unknown. By literature, GVV often occurred among

\footnotetext{
Manuscript accepted for publication September 19, 2012

${ }^{a}$ Department of Dermatology and Cosmetology, The 309th Hospital of Chinese People's Liberation Army, Beijing, 100091, China

${ }^{\mathrm{b}}$ These authors contributed equally to this work

${ }^{\mathrm{c} C}$ Corresponding author: Hui-Jun Ma, Department of Dermatology and Cosmetology, The 309th Hospital of Chinese People's Liberation Army, A17 Heishanhu Road, Haidian District, Beijing, 100091, P.R.

China. Email: melanocytes@163.com
}

doi: http://dx.doi.org/10.4021/jmc813w transplanted patients and Human immunodeficiency virus (HIV) infected patients $[2,3]$. On the other hand, butcher's warts are often larger than common warts. These warts usually occur in people whose occupation is related to handling of meat, poultry, or fish products [1]. We herein report a healthy middle-aged man with GVV who had been misdiagnosed as eczema and treated with topical glucocorticoids uninterruptedly for 4 years. We suggest that the prolonged exposure of topical glucocorticoids might associate with the formation of GVV.

\section{Case Report}

A 49-year-old man had complained of a growing large flavotestaceous massy plaque covered with some nodules and many crusts on the shin of his left leg for nearly 4 years at our clinic. Since 2006, the patient had arisen with some pruritic red papules on the shin of his left leg without any treatment. Later, the lesion was developed into local phaneropruritic erythema and maculopapules progressively. He had been diagnosed as eczema at the local hospital. Then, A simple anti-allergic therapy and topical fluocinolone acetonide and halometasone application were applied twice daily on these lesions. After continual scratching and applying these glucocorticoids alternately for 4 years, a large massy plaque covered with nodules and crusts were gradually developed. Furthermore, the lesion was thickening and expanding further. The patient was otherwise healthy and denied any occupational history of meat-handle before. No medical history of trauma and similar family history were reported.

Systemic and laboratory examinations revealed normal data. Tissue biopsy cultures were negative for fungi, atypical mycobacteria, and mycobacterium tuberculosis. On dermatological examination, a well-defined, flavotestaceous-color, $5 \times 5 \mathrm{~cm}$ sized, massy plaque covered with some nodules and crusts without hemorrhage was observed on the shin of his left leg. (Fig.1). An obsolete granulation tissue was found around the basement of one nodule but no evident erosion and ulcer. A biopsy specimen was taken from the margin of the plaque. Histopathologic examination showed crusts, hyperkeratosis, acanthosis and papillomatosis in epidermis 


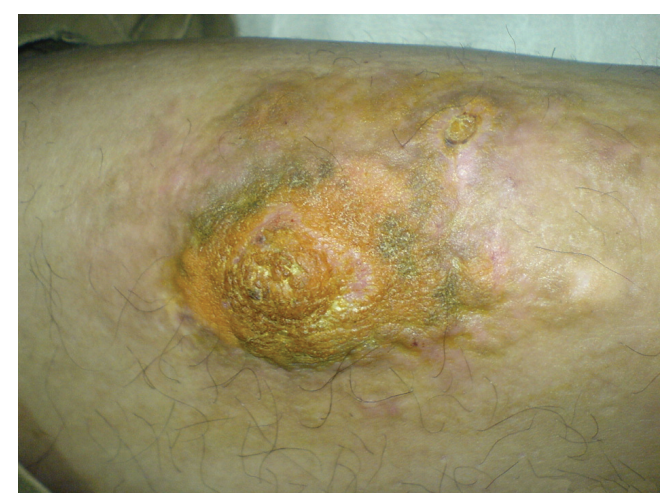

Figure 1. A well-defined, flavotestaceous-color, $5 \times 5 \mathrm{~cm}$ sized, massy plaque covered with some nodules and crusts without hemorrhage present on the shin of left leg.

(Fig.2a). At higher magnification, many physaliphorous cells, located on the upper-mid-dermis were detected and neither malignancy nor cytological atypia were observed (Fig.2b). The histopathology was typical for VV.

The patient was refused to be treated with liquid nitrogen firstly because of pain terror. So we applied topical ftibamzone and penciclovir (well-distributed mixing proportion 1:1, twice daily) instead of glucocorticoids for the lesion. Interestingly, we found that the plaque gradually stopped progressing and then regressed a little within 4 months. A cryotherapy and topical imiquimod therapy was strongly recommended. Finally, the patient received the therapeutic regimen. The skin lesion was totally healed after 2 months treatment.

\section{Discussion}

Verrucae vulgares occur as solitary or multiple, endophytic, or exophytic lesions predominantly seen in children and adolescents. Although the lesions are usually 2 to $10 \mathrm{~mm}$ in diameter, they can grow up to a GVV whose size is larger than
$1 \mathrm{~cm}$ [4]. However, there is few cases of GVV reported in the published work and its pathogenesis is largely unknown. By literature, GVV often occurred among transplanted patients and Human immunodeficiency virus (HIV) infected patients $[2,3,5]$. So some researches revealed that there is close relationship between GVV and immunosuppression $[2,3,5]$. On the other hand, butcher's warts are often larger than common warts. These warts usually occur in people whose occupation is related to handling of meat, poultry, or fish products $[1,4]$. In butcher's warts, HPV 2 was the most frequently isolated type in Jablonska's study [1]. Lei et al [6] revealed that the promoter activities of the HPV2 isolates from patients with GVV were remarkably increased compared with the HPV2a prototype. They speculate that increased promoter activities are linked, at least partially, with the clinical phenotypes of the uncommonly GVV.

In our case, the lesion was misdiagnosed with eczema and continuously applied topical fluocinolone acetonide and halometasone for nearly 4 years. Interestingly, discontinuation exposure to topical glucocorticoid was sufficient to stop the progressing of the eruption and regressed slowly within 4 month. In view of such above proofs, we speculate that scratching and prolonged exposure of topical glucocorticoids in the case might contribute the formation of GVV.

There is little information about HPV infection after long-term exposure to glucocorticoid has been reported in the published work. von Krogh et al [7] discovered that the prevalence of HPV DNA in the biopsies of of genital lichen sclerosus and erosive lichen planus was increased significantly after long term clobetasol therapy. Meanwhile, Bromberg-White et al [8] showed that the upstream regulatory regions of HPV31 were inducible by dexamethasone in differentiating keratinocytes. Bromberg-White believed that glucocorticoids may play an important role in the differentiation-dependent life cycle of HPV. Another studies also showed that multiple recalcitrant warts during Cushing's disease had a complete resolution after a 6-month therapeutic trial with anti-cortisolic drug ketoconazole [9]. The author indicated that anti-cortisolic treatment may correct endog-

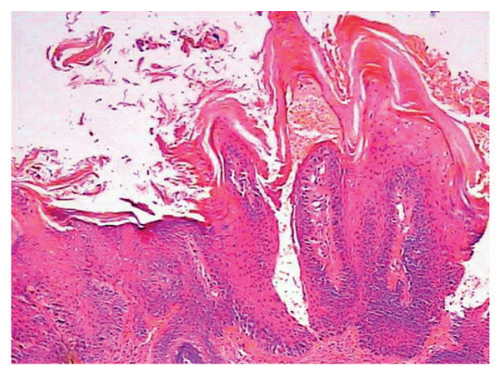

a

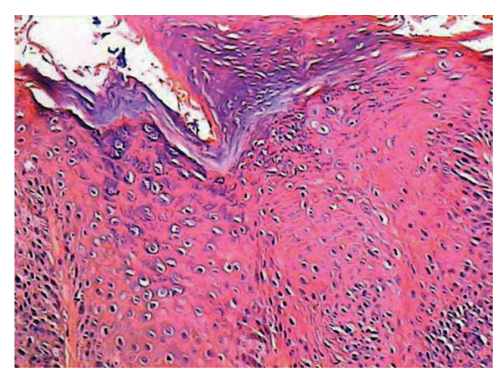

b

Figure 2. (a) Scanning magnification shows crusts, hyperkeratosis, parakeratosis, acanthosis and papillomatosis in the epidermis (haematoxylin and eosin; original magnification $\times 100$ ); (b) Higher magnification shows many physaliphorous cells, located on the upper-mid-dermis without malignancy and cytological atypia. (haematoxylin and eosin; original magnification $\times 250$ ). 
enous hypercortisolism and improve immunological status [9]. We believed that the prolonged exposure of topical glucocorticoids might destroyed the local immunology of skin and partly reactivate the HPV and provoke GVV formation at last. A large blind controlled study is necessary to test the hypothesis of association between glucocorticoids and GVV.

In the differential diagnosis of a GVV on the leg, warty tuberculosis (tuberculosis verrucosa cutis), deep mycosis and especially blastomycosis, blastomycosis-like pyoderma, and verrucous carcinoma should be considered. In addition, clinically GVV may mimic many other diseases depending on the localization such as vascular fibroma, even neurotrophic foot ulcer $[10,11]$. To the best of our knowledge, this is the first reported case about GVV on the leg mimicking eczema. On the other hand, VV is associated with the development of verrucous carcinoma, or classic warts may show malignant transformation [12].

In our case, the lesion was isolated, chronic, and circumscribed with inflammatory reaction and unresponsive to glucocorticoids treatments. Therefore, we considered the diagnoses of eczema, warty tuberculosis, deep mycosis and verrucous carcinoma besides GVV. We herein emphasize that skin biopsy from adequately deep and multiple sites to exclude underlying malignancy should be performed on all giant, chronic, isolated, recalcitrant eruption before therapy is initiated.

\section{References}

1. Ergun SS, Su O, Buyukbabany N. Giant verruca vulgaris. Dermatol Surg. 2004;30(3):459-462.

2. Kostaki M, Venetz JP, Nseir G, Meylan P, Sahli R, Pascual M, Laffitte E. Giant warts in a kidney transplant patient: regression with sirolimus. $\mathrm{Br} \mathrm{J}$ Dermatol. 2010;162(5):1148-1150.
3. Simone CD, Capizzi R, Carbone A, Fossati B, Valenzano $\mathrm{F}$, Amerio P. Use of acitretin in a case of giant common warts in an HIV-infected patient. Eur J Dermatol. 2008;18(3):346-347.

4. Lowy DR, Androphy EJ. Dermatology in General Medicine, 4th ed. New York: McGraw-Hill, 1993:2611.

5. Barba A, Tessari G, Talamini G, Chieregato GC. Analysis of risk factors for cutaneous warts in renal transplant recipients. Nephron. 1997;77(4):422-426.

6. Lei YJ, Wang C, Gao C, Jiang HY, Chen JM, Han J, Yuan YK, et al. HPV-2 isolates from patients with huge verrucae vulgaris possess stronger promoter activities. Intervirology. 2007;50(5):353-360.

7. von Krogh G, Dahlman-Ghozlan K, Syrjanen S. Potential human papillomavirus reactivation following topical corticosteroid therapy of genital lichen sclerosus and erosive lichen planus. J Eur Acad Dermatol Venereol. 2002;16(2):130-133.

8. Bromberg-White JL, Sen E, Alam S, Bodily JM, Meyers $C$. Induction of the upstream regulatory region of human papillomavirus type 31 by dexamethasone is differentiation dependent. J Virol. 2003;77(20):1097510983.

9. Joubert M, Bravard P, Reznik Y. 'Anti-cortisolic' treatment of warts. J Eur Acad Dermatol Venereol. 2008;22(4):511-512.

10. Lewis JE. Giant verruca vulgaris presenting as a neurotrophic foot ulcer. Cutis. 1982;30(5):638-640.

11. Vandeweyer E, Sales F, Deraemaecker R. Cutaneous verrucous carcinoma. Br J Plast Surg. 2001;54(2):168170 .

12. Noel JC, Detremmerie O, Peny MO, Candaele M, Verhest A, Heenen M, De Dobbeleer G. Transformation of common warts into squamous cell carcinoma on sun-exposed areas in an immunosuppressed patient. Dermatology. 1994;189(3):308-311. 